\title{
CULTURA GERAL E ESCOLA UNITÁRIA EM GRAMSCI
}

\author{
Jarbas Mauricio Gomes ${ }^{1}$ \\ UFSCar
}

\begin{abstract}
RESUMO
Este texto analisa o pensamento educacional do italiano Antonio Gramsci (1891-1937), explora a relação entre a questão cultural e o programa educativo gramsciano, a Escola Unitária. O texto está estruturado em três partes: a primeira, é uma breve caracterização da obra de Gramsci e de sua publicação no Brasil; a segunda, explora a questão cultural em Gramsci a partir dos escritos pré-carcerários e evidencia o papel da cultura na educação das novas gerações; a terceira, trabalha a relação entre a questão cultural e a concepção gramsciana de Escola Unitária, destacando a defesa de Gramsci por uma escola única, gratuita e de qualidade para todos. Uma escola voltada para a formação integral do homem, capaz de difundir a cultura geral e humanista, garantir a aquisição da disciplina (de estudo) e da autonomia necessárias ao desenvolvimento físico e intelectual das novas gerações.

Palavras-Chave: Antonio Gramsci; Escola Unitária; Cultura.
\end{abstract}

\section{GENERAL CULTURE AND UNITARY SCHOOL IN GRAMSCI}

\begin{abstract}
The current study analysis the Antonio Gramsci's educational thought (1891-1937) and explores the relation between cultural issue and the gramscian's educative program, the Unitary School, and highlights its dialectical character. It's a reading of the Gramsci's work that demonstrated the dialectical character of his thought. By proposing the Unitary School, Gramsci defended a free and quality school for everyone it was able to promoting a pedagogical work in the appropriation of the general culture, humanist, serve as an instrument for the acquisition of discipline and the autonomy necessary to the physical and intellectual development of the new generations.
\end{abstract}

Keywords: Antonio Gramsci. Unitary School. Culture.

\section{Introdução}

O presente texto é dedicado ao pensamento educacional de Antonio Gramsci (18911937) e se origina de um trabalho de leitura e análise de sua obra e explora a relação entre duas categorias do pensamento gramsciano, Cultura Geral e Escola Unitária. O caminho de investigação e análise a ser seguido não se prende à exposição dos fundamentos teóricopedagógicos de organização do programa educativo de Gramsci sintetizado na concepção de Escola Unitária. Pauta-se, antes, pela tarefa de evidenciar como a elaboração de um programa educacional revolucionário, completo em sua elaboração mas em construção permanente em função das transformações sociais e econômicas, desenvolve-se a partir do contexto histórico, em que as variáveis econômicas, políticas, filosóficas, artísticas, enfim, culturais, atuam ora como causa da conservação, ora como o causa das transformações das estruturas sociais e econômicas de uma sociedade. 
O Brasil vivencia o fim de uma década de esforços dedicados a efetivação de um Plano Nacional da Educação (PNE), um período de efetivo debate sobre os rumos da educação nacional. Os novos horizontes que se apresentam para o próximo ano, com o anúncio da II Conferência Nacional de Educação (CONAE) cujo tema é "O PNE na articulação do Sistema Nacional de Educação: participação popular, cooperação federativa e regime de colaboração", acirram os debates sobre a educação que almejamos.

Em meio a esta construção, que é tanto intelectual como prática, o debate acadêmico sobre a estrutura e organização da educação escolar se entrelaça à efetivação de políticas públicas para a Educação Básica. Ciência e política, isto é, pensamento e ação se desvelam em um movimento repleto de contradições que se materializam na realidade educacional vivenciada por estudantes e professores nas instituições escolares brasileiras. $\mathrm{Na}$ última década, as políticas públicas levantando a bandeira da democratização da educação promoveram a integração gradativa e progressiva da profissionalização no ensino médio brasileiro tendo como justificativa a função social da educação.

Tendo em vista o contexto atual da educação brasileira e procurando se situar em meio a este debate sobre a educação no Brasil, volta-se aqui para as proposições teóricas de Gramsci. Um pensador que, considerado um clássico do pensamento político italiano do século XX, defendeu uma educação escolar gratuita e qualidade para todos e, como consequência dessa defesa, elaborou um programa educativo de cunho humanista com vistas à formação integral do homem. Para contextualizar esta proposição de Gramsci e analisar a relação entre a formação cultural das novas gerações e o programa gramsciano de Escola Unitária este texto encontra-se articulado e estruturado a partir de uma tríade conceitual que envolve as noções de marxismo, cultura e educação presentes nos textos de Gramsci e explora o esforço teórico de conceituação e ressignificação empreendido por ele a estes temas. A escolha desta tríade conceitual - marxismo, cultura e educação - é decorrente da constatação de que a concepção gramsciana de Escola Unitária é resultado de uma análise profundamente arraigada na concepção materialista da história sobre o papel e a influência da cultura nos processos de transformação histórica.

Trilhar a reflexão de Gramsci sobre a educação, ou sobre outros temas seja de natureza política, sociologia ou filosófica, requer que se tenha em conta a concepção dialética de seu pensamento que em sua gênese é revolucionário e possui uma relação própria com as teses marxianas. Pensar a concepção gramsciana de uma Escola Unitária requer o reconhecimento do quanto esse programa educativo é revolucionário, encontra-se permeada de sentido político e se configura como a expressão de uma critica radical ao modelo educacional proposto pela burguesia italiana e a partir dele ao contexto político e econômico da primeira metade do século XX.

\section{A obra de Gramsci}

Antes de adentrar nas análises sobre a relação entre a questão cultural e a concepção de Escola Unitária, cabe aqui apresentar algumas considerações sobre a obra de Gramsci e a publicação desta no Brasil. Atualmente os textos de Gramsci são apresentados em três conjuntos, divididos primeiramente por cronologia e depois por finalidade. São eles os Escritos Políticos, as Cartas do Cárcere e os Cadernos Cárcere. A classificação cronológica tem como marco divisório o momento de sua prisão em 8 de novembro de 1926. Tem-se então, textos produzidos antes da prisão, denominados de escritos précarcerários (1910-1926), e textos produzidos na prisão, conhecidos como escritos do cárcere (1926-1937). 
O primeiro conjunto de textos é composto pelos escritos pré-carcerários e é conhecido, para além de sua posição cronológica, como Escritos Políticos. Isso se deve ao fato de que foram produzidos no calor da militância e em sua maioria foram publicados na imprensa socialista da época. No Brasil, os Escritos Políticos foram publicados em dois volumes, totalizando mais de mil páginas, organizadas por Carlos Nelson Coutinho. Devese ressaltar que, no entanto, trata-se de uma coletânea dos Escritos Políticos e, embora seja a edição brasileira mais completa, ela não contém todos os textos produzidos e publicados por Gramsci no período.

Os escritos do cárcere, compostos pelo segundo e o terceiro conjunto, também merecem algumas considerações sobre suas particularidades. O segundo conjunto é conhecido como Cartas do Cárcere, um conjunto que hoje soma 494 cartas redigidas por Gramsci aos familiares e alguns membros do Partido Comunista Italiano, dentre os quais se destaca a figura de Piero Sraffa (1898-1983), amigo de Gramsci e professor de Cambridge. No Brasil, as cartas foram publicadas integralmente, sob a organização de Coutinho e em dois volumes. O terceiro conjunto dos escritos gramscianos é composto pelos Cadernos do Cárcere, um total de 33 cadernos escolares nos quais Gramsci anotou as análises que desenvolveu durante o período em que este recluso (1926-1937). No Brasil, os cadernos foram publicados em seis volumes, porém, os critérios de organização e a sua publicação parcial suscitam debates acalorados entre os estudiosos do pensamento de Gramsci.

Ao todo, a edição brasileira dos escritos de Gramsci é composta por dez volumes, sistematizados de acordo com a descrição acima ${ }^{2}$. Ainda que seja reconhecido os méritos deste trabalho editorial, que serviu para difundir ainda mais os escritos de Gramsci no Brasil e aproximar os leitores de sua obra, deve-se fazer uma ressalva em relação aos volumes referentes aos Cadernos do Cárcere. No Brasil as notas dos cadernos não foram publicadas integralmente, privilegiou-se a publicação das anotações mais sistemáticas que começaram a ser compostas por Gramsci em 1932 a partir do Caderno 10 e que se estenderam até o Caderno 29. Para um leitor desavisado que inicie a leitura pelo volume 2 da edição brasileira, que contém o conhecido Caderno 12, sem proceder a leitura da esclarecedora introdução redigida por Carlos Nelson Coutinho que compõe o primeiro volume, o entendimento dos textos pode ser dificultado em função da forma como foram dispostos na edição brasileira e, também, pelas características do texto original.

Os Cadernos do Cárcere foram escritos inicialmente como um conjunto de notas, distribuídas em vinte e nove cadernos. Três cadernos foram utilizados por Gramsci em exercícios de Tradução. Nos primeiros cadernos, não há um grande texto sistematizado, mas um conjunto de notas denominadas de miscelâneas ou notas esparsas que abordam os mais diferentes temas, da cultura a política, da filosofia a literatura. Foi a partir do Caderno 8 que Gramsci se propôs a sistematizar seus escritos em Cadernos Especiais, organizados de acordo com temas pré-estabelecidos: Filosofia, História dos Intelectuais, Literatura, Folclore dentre outros. Este trabalho de sistematização iniciado a partir do Caderno 10, levou Gramsci a retomar alguns textos que compunham os cadernos anteriores e os integrar aos Cadernos Especiais que estava redigindo. Este é o caso do Caderno 12, que contém em seu texto reelaborações de notas que foram apresentadas inicialmente no Caderno 4. Em função disso, a maioria das edições dos Cadernos do Cárcere publicaram apenas os Cadernos Especiais. No caso desta edição brasileira, as notas esparsas que não foram assimiladas pelas sistematizações empreendidas por Gramsci na composição dos Cadernos Especiais e tivessem relação com a temática do volume foram publicadas em sequência após os cadernos especiais. 
O resultado prático desta organização editorial é que, de certo modo, o leitor tem acesso a todos os temas tratados por Gramsci nos Cadernos, mesmo que suas notas não tenham sido publicadas integralmente. Por outro lado, significa que o leitor que toma a edição brasileira como base, tem uma visão limitada daquilo que foi a produção teórica de Gramsci no cárcere e, em função da organização editorial, não consegue visualizar o processo de elaboração que submeteu suas notas. Em muitos casos, por não ter conhecimento das condições em que as notas foram escritas, chega-se a conceber que ele tenha escrito livros ou artigos sobre os temas abordados. Ainda que o debate sobre essa questão remeta a problemas de natureza epistemológica para o estudo de Gramsci ${ }^{3}$.

A difusão do pensamento de Gramsci no campo educacional brasileiro teve seu maior impulso na década de 1980, quando suas ideias serviram de fundamento para a construção de propostas educacionais que se tornaram hegemônicas no campo da educação brasileira ao longo das décadas seguintes e se consolidaram como programas de governo. O cenário de efervescência política vivido na segunda metade da década de 1980, marcado pela redemocratização do país, estimulou a apropriação das ideias de Gramsci pelos educadores. O tempo, no entanto, logo revelou que a falta de condições materiais necessárias ao estudo sistemático de seu pensamento deu origem a uma apropriação indireta, distante de seus textos ${ }^{4}$. Como consequência, o pensamento educacional gramsciano foi esvaziado de seu conteúdo político e revolucionário e as suas ideias assumiram o caráter de teoria pedagógica (MAGRONE, 1996). O esvaziamento da concepção revolucionária de Gramsci pode ter facilitado a positivação de suas ideias e, consequentemente, originado uma série de leituras descontextualizadas (NOSELLA, 2004; MANACORDA, 2008).

O marco histórico das análises de Gramsci sobre a educação foi o Risorgimento ${ }^{5}$ e a unificação do Estado italiano consolidada em 1861. A unificação ainda era recente quando, nas primeiras décadas do século XX, os socialistas mediam forças com os intelectuais liberais na luta contra a organização político-econômica liberal-capitalista que se estabelecia na Itália (RIAL, 1997). Deter o controle do Estado laico e liberal recém formado era a máxima expressão da ascensão da burguesia como grupo hegemônico, seja em relação à estrutura tradicional do catolicismo e de sua influência sobre o Estado, seja em relação às investidas dos proletários organizados sob a bandeira do socialismo.

Gramsci entendia que, uma vez no poder, a burguesia italiana não tardou a adotar políticas cujos resultados tinham a clara intenção de promover a manutenção dos privilégios de uma classe social sobre as demais. Gramsci, engajado na luta pela superação da concepção burguesa de mundo e de todas as consequências dela decorrentes, concebia a formação cultural dos proletários como um requisito necessário para a efetivação da revolução proletária. Deve-se ter em conta que ao tratar da formação cultural dos proletários, e de modo mais abrangente das classes subalternas, Gramsci pensava na educação das novas gerações para além da formação política que, em sua visão, deveria ser ofertada pelo Partido. Em sua produção teórica ele defendeu que o êxito da revolução proletária dependia da união entre os trabalhadores industriais e camponeses e da superação da concepção hegemônica de mundo, possível somente mediante uma sólida formação cultural que permitisse aos trabalhadores desenvolver um pensamento crítico sobre sua concepção de mundo, pela elaboração da filosofia da práxis. 


\section{A questão cultural no pensamento de Antonio Gramsci}

Os temas relativos à questão cultural e a educação podem ser encontrados ao longo de toda a produção teórica de Gramsci, isto é, tanto nos Escritos Políticos, quanto nas Cartas e nos Cadernos do Cárcere. Embora a presença destes dois temas esteja difusa e seja fragmentada, já que Gramsci não escreveu uma obra específica sobre a cultura ou sobre a educação, suas análises possuem uma unidade teórica que pode ser estabelecida a partir de um ponto de inflexão de seu pensamento, isto é, os fundamentos metodológicos de sua análise.

Um dos fundamentos metodológicos de sua análise é o emprego da concepção dialética da história em suas investigações. Pelo emprego da dialética Gramsci procurou evidenciar como fenômenos particulares da cultura e da educação, assim como da organização da vida social italiana, continham em si a expressão das contradições da sociedade de seu tempo, do movimento histórico. Outro aspecto caro ao pensamento gramsciano, reside no fato de que a sua análise dialética está fundada em um historicismo que, ao ver de Giuseppe Cacciatore (2009), consiste em uma estrutura articulada de reflexão crítica que concebe a gênese e a consolidação da cultura moderna a partir de um percurso histórico complexo e acidentado.

Gramsci examinava fenômenos pontuais da sociedade italiana considerando as relações entre estes e a totalidade dos fenômenos que compõem a realidade cultural, política e econômica, tal qual apontara Karl Marx no Prefácio à Contribuição à Crítica da economia política onde destacou que "[...] o leitor que se dispuser me seguir terá que se decidir a se elevar do particular ao geral [...]". (MARX, 2013. p. 46). Gramsci, consequentemente, seguindo a proposta de Marx, conduziu suas análises do particular para o geral de modo que as análises do fenômeno educacional, por si, servem para esboçar ou desvelar o contexto geral das contradições de ordem política e econômica da sociedade italiana.

Em suas análises sobre a questão educacional, Gramsci identificou que a necessidade de produção material da própria existência gerava a impossibilidade dos filhos das classes subalternas se dedicarem exclusivamente ao estudo da cultura de maneira desinteressada. Por outro lado, identificou também que, incentivada pelo ideal liberal da burguesia italiana, a juventude valorizava mais a educação escolar voltada à inserção profissional porque esta, ao contrário de uma educação desinteressada de cultura geral, atendia suas demandas imediatas (NOSELLA, 2011). Tal qual, apontara Marx em suas análises.

[...] na produção social da própria existência, os homens entram em relações determinadas, necessárias, independente de sua vontade; essas relações de produção correspondem a um grau determinado de desenvolvimento de suas forças produtivas materiais. [...] O modo de produção da vida material condiciona o processo de vida social, política e intelectual [...]. (MARX, 2013. p. 47).

Os elementos do método gramsciano e de sua relação com a síntese marxiana tem sido amplamente discutido por estudiosos do pensamento de Gramsci que destacam a necessidade de analisá-lo considerando a matriz teórica a partir da qual desenvolveu suas ideias (GERRATANA, 1997; LIGUORI, 2007; FROSINI, 2009), considerações pertinentes também para as análises de seu pensamento educacional (NOSELLA, 2004). 
No pensamento gramsciano, em especial nos Cadernos do Cárcere, o conceito de cultura aparece sempre relacionado a um amplo leque de categorias conceituais como hegemonia, política, filosofia, bloco histórico, sociedade política e sociedade civil que, dentre outros, apresentam a cultura como uma expressão da sociedade (BARATTA, 2009). As análises de Gramsci sobre a cultura, no entanto, inserem-se em um movimento histórico de amadurecimento da concepção de cultura a partir do qual essa passou a ser concebida como a soma dos saberes produzidos, acumulados e sistematizados pela humanidade.

Esse movimento se intensificou no decorrer do século XVIII e foi libertando a noção de cultura de adjetivos como arte, letras ou ciências até que esta passou a ser entendida como formação ou educação do espírito. Essa evolução na interpretação da noção de cultura permitiu a superação de uma visão naturalista do homem e promoveu o desenvolvimento de uma interpretação da história que passou a distinguir o homem pela sua condição cultural, o que influenciou o estabelecimento de uma noção científica de cultura ao longo do século XIX (CUCHE, 1999). A concepção científica de cultura foi definida por Edward Burnett Tylor (1832-1917) no primeiro capítulo de seu livro Cultura primitiva: pesquisas sobre o desenvolvimento da mitologia, filosofia, religião, linguagem, arte e costume, publicado em $1871^{6}$ :

Cultura ou Civilização, tomada em seu mais amplo sentido etnográfico, é aquele todo complexo que inclui conhecimento, crença, arte, moral, lei, costume e quaisquer outras capacidades e hábitos adquiridos pelo homem na condição de membro da sociedade. (TYLOR, 2005. p. 69).

A concepção de cultura de Tylor (2005) é antropológica, universalista e equipara os termos Kultur do alemão e Civilization do francês ${ }^{7}$. Sem descuidar da noção de que a cultura vem da racionalidade e da ação, a concepção de cultura predominante no século XIX remetia à ideia de que a formação de uma nação cultural precede a existência de uma nação efetivamente política, perspectiva que é decorrente do resultado da apropriação das noções de Kultur e Civilization (CUCHE, 1999). No caso da situação italiana, a unidade política se deu antes da unidade cultural (RIAL, 1997), sendo a questão da unificação da cultura um tema de grande importância para a criação da identidade do povo italiano (MANACORDA, 2008; NOSELLA, 2004). No caso da revolução proletária na Itália, dificuldades como a falta de domínio da língua italiana se configuravam como um obstáculo a ser superado pelo movimento socialista.

Da noção de Kultur, sobressaiu a ideia de que a cultura é um conjunto de conquistas artísticas, intelectuais e morais, patrimônio de uma nação que, uma vez adquirido, torna-se o motivo de sua unidade; a concepção de Civilization contribuiu para o enriquecimento da noção de cultura ao lhe conferir a dimensão da coletividade. A cultura, a partir de então, não se refere mais apenas ao desenvolvimento intelectual, mas aos caracteres próprios do desenvolvimento de uma comunidade, Estado ou Nação, em um sentido amplo, vasto e muitas vezes impreciso (CUCHE, 1999).

A concepção científica de cultura de Tylor (2005) efetivou a dessacralização da história e da filosofia que, ao se libertarem da teologia, passaram a produzir respostas objetivas para a questão da diversidade humana e, de modo universalista, tornou-se a expressão da totalidade da vida humana. Essa dimensão da cultura fomentou a apreensão da totalidade do desenvolvimento humano pela determinação, mesmo que grosseira, dos estágios da evolução da cultura. A ideia que se apresenta é a de que existe uma continuidade entre a cultura primitiva e as culturas mais avançadas, isto é, que existe um 
processo de evolução cultural pelo qual os sujeitos se libertam das concepções primitivas e religiosas e avançam em direção a uma cultura racional, de cunho filosófico e científico (CUCHE, 1999).

Foi na luta pela superação da concepção de mundo hegemônica, vinculada ao catolicismo e a religiosidade que Gramsci pensou a formação cultural dos subalternos (GOMES, 2012). A formação voltada à apropriação da alta cultura de cunho filosófico e científico produzida pela humanidade ao longo de sua história permitiria a passagem de uma visão de mundo desagregada para uma elaboração filosófica que possibilitaria ao homem tomar consciência de sua própria existência, tornando-se senhor de si mesmo, como escreveu Gramsci, ainda menino em 1910, no texto Oprimidos e opressores, o primeiro do conjunto dos Escritos Políticos: “[...] O homem, que em certo momento se sente forte, com a consciência da própria responsabilidade e do próprio valor, não quer que nenhum outro lhe imponha sua vontade e pretenda controlar suas ações e seus pensamentos [...]. (GRAMSCI, 2004. p. 43).

Se a questão do papel da formação cultural já pode ser rastreada em sua reflexão juvenil de 1910, anos mais tarde, em dezembro de 1916, no texto Homens ou Máquinas? Gramsci teceu duras críticas a omissão do Partido Socialista Italiano (PSI) em relação às questões voltadas a formação cultural e escolar dos proletários italianos e chamou a atenção para a necessidade de se elaborar um programa escolar diferente daqueles que já existiam. No texto Homens ou Máquinas?, Gramsci ao mesmo tempo em que defendeu uma educação igualitária para todos, denunciava que a escola italiana das duas primeiras décadas do século XX, mesmo sendo financiada pelo Estado com recursos do tesouro nacional, continuava sendo de caráter burguês e não era acessível ao proletariado. Gramsci evidencia que "[...] A cultura é um privilégio. A escola é um privilégio. E não queremos que seja assim. Todos os jovens deveriam ser iguais diante da cultura [...]" (GRAMSCI, 2004. p. 74). Ainda que sua bandeira de luta de Gramsci seja a formação dos proletários, a luta pela escola era para todos, Gramsci reivindicava uma escola gratuita e de qualidade, com base humanista: "O proletariado precisa de uma escola desinteressada. Na qual seja dada à criança a possibilidade de ter uma formação, de tornar-se homem, de adquirir aqueles critérios gerais que servem para o desenvolvimento do caráter" (GRAMSCI, 2004. p. 75).

Cultura e educação escolar estão intrinsecamente ligadas no pensamento de Gramsci, o que remete a relação entre cultura e hegemonia. Gramsci pensava a cultura como a expressão de uma sociedade em um momento histórico determinado e tinha consciência da existência de manifestações culturais próprias do capitalismo cujo fim era a manutenção de sua hegemonia (ANGELI, 2011). Nesse sentido, a cultura é entendida, no pensamento de Gramsci, como um saber que transforma e produz um pensamento criador quando se encontra em relação com a ação. A cultura detém em si a potencialidade da crítica, pois ao se constituir ela é capaz de dotar seu portador de uma reflexão filosófica de cunho ontológico a partir da qual o sujeito, ao mesmo tempo em que se apropriar da cultura, executa um exercício de reflexão e análise sobre a sua própria história (SCHLESENER, 2002).

Esta visão de cultura, fundada em um historicismo absoluto (ANGELI, 2011), enfatiza a filiação marxista de Gramsci que reapresentava o homem como produtor da própria história e, consequentemente, produtor de sua própria cultura (NOSELLA, 2004). Esse é o fundamento da crítica de Gramsci à formação cultural italiana que, de cunho elitista, concebia a cultura como um saber enciclopédico do qual o homem era apenas um 
recipiente a ser preenchido por um saber estanque que, mesmo fundamentado em dados empíricos, eram apresentados em forma de fatos brutos e desconexos.

No texto Socialismo e Cultura de 29 de janeiro de 1916, Gramsci discutiu o papel da cultura na formação da consciência dos trabalhadores. Sua crítica se dirigia a toda organização cultural que se instituía na Itália sob a influência religiosa do catolicismo, em especial àquela que fazia da cultura um simulacro de erudição. Gramsci apresentou a decadência dessa concepção citando o exemplo do jovem que ao saber um pouco de latim, despejava sua falsa erudição sobre aqueles que mal conheciam os rudimentos da própria língua italiana e, presos aos dialetos regionais, sentiam-se acuados por um modelo de cultura que Gramsci denominou de intelectualismo pedante.

É preciso perder o hábito e deixar de conceber a cultura como saber enciclopédico, no qual o homem é visto apenas sob a forma de um recipiente [...]. Essa forma de cultura é realmente prejudicial, sobretudo para o proletariado. Serve apenas para criar marginais, pessoas que acreditam ser superiores ao resto da humanidade porque acumularam na memória um certo número de dados e de datas que vomitam em cada ocasião [...]. O estudantezinho que sabe um pouco de latim e de história, o rábula que conseguiu obter um diploma graças à irresponsabilidade e à desatenção dos professores acreditam ser diferentes, superiores até mesmo ao melhor operário qualificado, que cumpre na vida uma tarefa bem precisa e indispensável e que vale cem vezes mais em sua atividade do que os outros valem na deles. Mas isso não e cultura, é pedantismo; não é inteligência, mas intelectualismo - e é com toda razão que se reage contra isso. (GRAMSCI, 2004. p. 57-58).

A exibição pedante de uma cultura intelectualista era apontada por Gramsci como um instrumento de coerção sobre os trabalhadores que, mesmo desenvolvendo uma atividade essencial no mundo da produção, sentiam-se coagidos diante de certas demonstrações de tal simulacro de erudição. Em contraposição a esse modelo de cultura e tomando a cultura em um sentido ontológico da ação intelectual, inerente a todo homem, ainda no texto Socialismo e cultura Gramsci apresentou a influência da formação cultural na capacidade de análise e compreensão do valor histórico de cada homem no desenvolvimento e na organização do mundo da produção, perspectiva já apontada em seu texto Oprimidos e opressores de 1910 onde apontava a relação entre a consciência de si e a liberdade. A concepção gramsciana de cultura possui uma relação intrínseca com a formação da consciência e com a reflexão do homem sobre sua própria existência. Essa reflexão é marcada por um teor filosófico e educativo que remete a outros dois conceitos que posteriormente aparecerão no discurso educacional de Gramsci: a disciplina e a formação da consciência.

Cultura é algo bem diverso. É organização, disciplina do próprio eu interior, apropriação da própria personalidade, conquista de consciência superior: e é graças a isso que alguém consegue compreender seu próprio valor histórico, sua própria função na vida, seus próprios direitos e deveres. Mas nada disso pode ocorrer por evolução espontânea, por ações e reações independentes da própria vontade, como ocorre na natureza vegetal e animal, onde cada ser singular seleciona e específica seus próprios órgãos inconscientemente, pela lei fatal das coisas. (GRAMSCI, 2004. p. 58). 
De encontro com a perspectiva de que a cultura não se desenvolve espontaneamente, mas é resultado de uma ação intencionalmente direcionada cujo fim é a apropriação tanto da disciplina como da autonomia, Gramsci escreveu em 15 de junho de 1918 o texto intitulado Livre pensamento e pensamento livre. Neste texto Gramsci polemizava a contradição presente entre as expressões: 'livre pensamento' e 'pensamento livre' e ao afirmar que, "O livre pensador é um utópico, ou seja, seu pensamento é escravo, ainda não saiu do caos da convencionalidade e do preconceito. Concebe a liberdade de modo estrito e limitado [...]" (GRAMSCI, 2004. p. 178), esboça a face mais desagregadora do intelectualismo pedante, cuja cultura não se sobressai a um simulacro de erudição ${ }^{8}$.

Em contraposição a face desagregadora do intelectualismo pedante, pela superação da concepção hegemônica de mundo e em defesa de sua concepção de cultura, Gramsci afirmava que os socialistas deveriam buscar a superação das certezas dogmáticas e absolutas, encaminhando-se para o desenvolvimento de um pensamento livre.

\begin{abstract}
Os socialistas, ao contrário, querem o 'pensamento livre'. Querem escapar de todas as convenções, de todas as estreitezas, de todos os preconceitos. Para eles, o pensamento em si e para si é sempre livre; mas livre não significa informe, não significa arbitrário. Portanto, mesmo sendo livre, o pensamento é condicionado; e é condicionado precisamente pela história. Uma opinião individual é condicionada pela específica cultura do individuo (ou seja, pela história particular daquele indivíduo) e encontra nessa cultura sua explicação e significado. Quanto mais a cultura de um indivíduo for sólida e ampla, mais suas opiniões estarão perto da verdade, ou seja poderão ser aceitas por todos; quanto mais numerosos forem os indivíduos de sólida e ampla cultura, tanto mais as opiniões difundidas se aproximarão da verdade, ou seja, conterão a verdade em forma imatura e imperfeita, que pode ser desenvolvida até a maturidade e a perfeição. (GRAMSCI, 2004. p. 178-179).
\end{abstract}

A concepção de cultura e a formação cultural defendidas por Gramsci estão ligadas diretamente a formação da consciência crítica e a compreensão das contradições. Essa forma de pensar a questão cultural, partindo da realidade efetiva das relações sociais e evidenciando as contradições latentes na organização social, política e econômica é resultado da análise dialética de natureza historicista empregada por Gramsci. Tal qual ele aponta ainda no texto Livre pensamento e pensamento livre ao afirmar que "Os socialistas, na medida em que pensam livremente, de modo historicista, compreendem a possibilidade da contradição e, por isso, mais facilmente a vencem, ampliando assim a esfera ideal e humana de suas próprias ideias [...]" (GRAMSCI, 2004. p. 179).

Esses e outros argumentos servem de ponto de partida para sustentar a afirmação de que no pensamento de Gramsci a formação cultural guarda relação com o trabalho educativo das instituições escolares. A ideia de que o direcionamento, a disciplina e a vontade são elementos essenciais na aquisição da cultura e de que uma suposta evolução espontânea seria um entrave para o desenvolvimento intelectual dos grupos subalternos é retomada por Gramsci nos Cadernos do Cárcere, incorporada a sua crítica a educação moderna. Os fundamentos dessa análise já estavam delineados por Gramsci no texto $\mathbf{O}$ nosso Marx de 4 de maio de 1918, escrito em função do centenário do nascimento de Marx. Nele, Gramsci apresentou as contradições existentes nas interpretações do 
pensamento de Marx, dentre as quais a de muitos socialistas, e apresentou os fundamentos do pensamento marxiano afirmando que

Com Marx, a história continua a ser domínio das idéias, do espírito, da atividade consciente dos indivíduos isolados ou associados. Mas as idéias, o espírito, ganham substância, perdem sua arbitrariedade, não são mais fictícias abstrações religiosas ou sociológicas. A sua substância está na economia, na atividade prática, nos sistemas e nas relações de produção e troca. A história como evento é pura atividade prática (econômica e moral) [...]. (GRAMSCI, 2004. p. 162).

O tratamento a questão cultural empreendido por Gramsci, deve ser analisado a partir das contradições latentes nos processo de aquisição e domínio da cultura, isto é, na intencionalidade dos processos de difusão e apropriação cultural que, ocorridos tanto no ambiente escolar quanto nas relações informais, estão circunscritos à concepção hegemônica de mundo e aos objetivos da classe dominante. Por isso Gramsci se dedicou a luta por uma educação integral de cultura geral gratuita para todos por meio de uma organização escolar que se contraponha vigorosamente ao modelo hegemônico organizado e ofertado de acordo com a concepção burguesa de mundo (NOSELLA, 2004).

No Caderno $10 \S 44$, intitulado Introdução ao estudo da filosofia, Gramsci trabalhou a relação entre a concepção de unitário e a questão cultural, chamando a atenção para o papel da linguagem como expressão da diversidade cultural. Gramsci afirma que "[...] Linguagem significa também cultura e filosofia (ainda que no nível do senso comum) e, portanto, o fato da 'linguagem' é, na realidade, uma multiplicidade de fatos mais ou menos organicamente coerentes e coordenados [...]" (GRAMSCI, 2007. p. 1130, tradução nossa). Gramsci enfatizou que a cultura tem o papel de unificar os indivíduos que se entendem entre si em maior ou menor grau, de modo que a linguagem comum pode se tornar um elo cultural unificador de caráter histórico e social ou um obstáculo a unificação dos povos. Tem-se aqui um elemento chave para a compreensão da relação entre a defesa que Gramsci faz da cultura geral e o programa educacional da Escola Unitária.

[...] a importância que tem o 'momento cultural' também na atividade prática (coletiva): todo ato histórico não pode deixar de ser realizado pelo 'homem coletivo', isto é, pressupõe a conquista de uma unidade 'culturalsocial' pela qual uma multiplicidade de vontades desagregadas, com fins heterogêneos, solda-se conjuntamente na busca de um mesmo fim, com base numa idêntica e comum concepção de mundo (geral e particular, transitoriamente operante por meio da emoção - ou permanente, de modo que a base intelectual esteja tão enraizada, assimilada e vivida que possa se transformar em paixão). Já que assim ocorre, revela-se a importância da questão linguística geral, isto é, da conquista coletiva de um mesmo 'clima' cultural. (GRAMSCI, 2007. p. 1330-1331, tradução nossa).

Gramsci almejava uma educação capaz de oferecer às novas gerações, inclusive aos subalternos, a possibilidade de aquisição da alta cultura. Ele defendeu que essa tarefa pertencia a escola que, Unitária, deveria instigar e fomentar a maturidade intelectual de jovens e crianças, aliando o desenvolvimento da capacidade de criação intelectual e prática com a iniciativa e a autonomia de orientação. Esses elementos expressam a contradição da organização escolar italiana praticada na década de 1920, na qual a formação da alta cultura e da intelectualidade era deixada para os estudos universitários, aos quais os 
subalternos não tinham acesso em função das necessidades efetivas de manutenção material de sua existência. Como resultado, os egressos da escola elementar e média que não tinham o pleno domínio da linguagem e por isso mesmo não transitavam entre os conhecimentos básicos da cultura geral, mantinham-se como um grupo desagregado e disperso e incapaz de ler o discurso hegemônico e de se contrapor a ele.

\section{A Escola Unitária: a cultura como questão educacional}

A questão cultural tratada por Gramsci nos Escritos Políticos assumiu nos Cadernos do cárcere uma conotação educativa e se transformou em uma questão escolar (DIAS, 2000), a partir da qual propôs a organização de uma Escola Unitária cujas ações tinham o fim de difundir a cultura geral entre as novas gerações (NOSELLA; AZEVEDO, 2012). Os elementos da concepção gramsciana de cultura aparecem na concepção de educação apresentada no Caderno 1 na nota $§ 123$, na qual ele propõem uma investigação sobre os princípios da pedagogia moderna. Nela Gramsci definiu a educação nos seguintes termos: “[...] a educação é uma luta contra os instintos ligados às funções biológicas elementares, uma luta contra a natureza, a fim de dominá-la e de criar o homem 'atual' à sua época [...]" (GRAMSCI, 2007. p. 114, tradução nossa).

A luta contra os instintos e a natureza humana, apregoada por esta concepção de educação previa a aquisição da alta cultura, apresentada por ele em seus textos précarcerários. Gramsci entendia que a organização e a disciplina de estudos são os elementos culturais que permitem ao homem exercer o domínio sobre as funções biológicas elementares, condição necessária para a formação da personalidade e a conquista da consciência superior pelos trabalhadores e pelas novas gerações das classes subalternas. Em suas análises sobre o sistema escolar italiano das primeiras décadas do século XX, Gramsci constatou que a educação escolar ofertada aos subalternos era incapaz de promover uma formação voltada ao desenvolvimento da disciplina de estudos e da apropriação da alta cultura, condições necessárias para o desenvolvimento da capacidade intelectual das novas gerações.

Tal situação era decorrente da reforma educacional promovida por Giovanni Gentile (1875-1944) e Giuseppe Lombardo-Radice (1879-1938), quando da ascensão do fascismo ao poder. $\mathrm{O}$ modelo escolar estabelecido promovia uma educação segregadora que, constituída a partir de dois sistemas educacionais distintos, a escola e a universidade, excluía imediatamente os subalternos, dada as condições efetivas de sua manutenção econômica (TOGNON, 1997). A crítica ao sistema escolar italiano apresentada no texto Homens ou Máquinas? de 1916 demonstrou que a cisão na escola italiana era um problema histórico que, agravado pela reforma educacional de Gentile e Lombardo-Radice, sempre limitara o acesso dos trabalhadores à cultura geral, incentivando-os a estudar em escolas paralelas de formação profissional, com vistas a sua empregabilidade e inserção no mundo da produção.

O proletariado, que está excluído das escolas de cultura média e superior por causa das atuais condições da sociedade, que determinam uma certa especialização entre os homens - especialização antinatural, já que não baseada na diferença de capacidades e, por isso, destruidora e prejudicial à produção -, tem de ingressar nas escolas paralelas: técnicas e profissionais. As escolas técnicas instituídas com critérios democráticos pelo ministro Casati, sofreram, em função das necessidades 
antidemocráticas do governo estatal, uma transformação que as desnaturou [...]. (GRAMSCI, 2004. p.74-75).

Ao retomar o tema no $\S 179$ do Caderno 6, Gramsci apresentou uma síntese dos debates ocorridos na Câmara dos Deputados italiana sobre a questão, evidenciando a situação de desagregação da escola média promovida pela organização escolar. Para Gramsci, a escola italiana sob o signo de democrática, promovia a exclusão social impedindo o acesso dos filhos dos subalternos aos níveis mais elevados da instrução escolar e consequentemente da cultura.

[...] nessa [discussão sobre a educação profissional] todos os elementos teóricos e práticos para o estudo do problema são aflorados de forma perspicaz e orgânica. Três tipos de escola: 1) profissional, 2) media técnica, 3) clássica. A primeira para os operários e camponeses, a segunda para os pequenos-burgueses e a terceira para a classe dirigente. (GRAMSCI, 2007. p. 825, tradução nossa).

A defesa gramsciana por uma escola desinteressada passa não só pela identificação de que no sistema educacional italiano da época a alta cultura era objeto de estudo apenas nas universidades e nas escolas médias destinas aos filhos da classe burguesa. Mas, encontra-se relacionada a dois outros fatores: 1) que a escola de alta cultura era financiada também pelos proletários que pagavam seus impostos; e, 2) no fato concreto de que mesmo que algum subalterno tenha acesso a essa escola, suas condições reais de estudo são proibitivas, como apresentou no texto Homens ou Máquinas?.

A escola média e superior, que são estatais - ou seja, pagas com os recursos do tesouro nacional e, portanto, também com os impostos diretos pagos pelo proletariado -, só podem ser freqüentadas pelos jovens filhos da burguesia, que desfrutam da independência econômica necessária para a tranqüilidade dos estudos. Um proletário, ainda que inteligente, ainda que com todas as condições necessárias para tornar-se homem de cultura, é obrigado ou a desperdiçar suas qualidades em outra atividade, ou a tornar-se um autodidata [...]. (GRAMSCI, 2004. p. 73-74).

A exposição de Gramsci evidencia a contradição presente na organização escolar italiana do início do século XX, de um lado uma escola profissionalizante que destinada aos filhos dos proletários era voltada para a qualificação profissional dos grupos subalternos com vistas ao seu consequente ingresso no mercado de trabalho e, de outro, uma escola de formação cultural desinteressada no trabalho, voltada para a educação dos filhos das elites política e econômica e cujo objetivo era formar dirigentes. Gramsci tinha clareza que a organização escolar italiana atendia as demandas da organização do capital e da produção em massa, para qual era "[...] mais útil ter operários-máquinas em vez de operários-homens” (GRAMSCI, 2004. p. 76).

Gramsci identificava que a tendência de suprir necessidades imediatas na qual a escola italiana estava submetida era a expressão de uma crise cultural. No entanto, a organização escolar italiana é a expressão cabal da hegemonia burguesa sobre as classes subalternas. O processo de exclusão dos proletários e das novas gerações de subalternos de uma escola de cultura geral desinteressada no trabalho é justificado por uma concepção de 
mundo que de maneira sistemática e intencional apresenta a escola profissionalizante como uma solução viável aos problemas econômicos das classes subalternas.

Para Gramsci esta era a contradição latente no discurso de defesa da educação profissionalizante italiana, fundada sobre uma democracia que tolhe das classes subalternas as possibilidades reais de entendimento das contradições imanentes na organização socialprodutiva do capitalismo e de sua superação, perpetuando as diferenças sociais. Em função disso sentenciou no Caderno $12 \S 1$ :

[...] $\mathrm{Na}$ escola atual, pela crise profunda da tradição cultural e da concepção da vida e do homem, verifica-se um processo de progressiva degenerescência: as escolas de tipo profissional, isto é, preocupadas em satisfazer interesses práticos imediatos, tomam a frente da escola formativa, imediatamente desinteressada. $\mathrm{O}$ aspecto mais paradoxal reside em que este novo tipo de escola aparece e é louvada como democrática, quando, na realidade, não só é destinada a perpetuar as diferenças sociais, como ainda a cristalizá-las em formas chinesas. (GRAMSCI, 2007. p. 1547, tradução nossa).

Gramsci considerou a organização escolar italiana de seu tempo antidemocrática. Tanto pela forma com a qual a burguesia ludibriou os grupos subalternos, aumentando da oferta dos cursos profissionalizantes, como por sua proposta de ascensão social por meio de uma formação escolar voltada à empregabilidade.

A multiplicação de tipos de escola profissional, portanto tende a eternizar as diferenças tradicionais; mas, dado que tende, nestas diferenças, a criar estratificações internas, faz nascer a impressão de ter uma tendência democrática. Por exemplo: operário manual e qualificado, camponês e agrimensor ou pequeno agrônomo, etc. [...]. (GRAMSCI, 2007. p. 1547, tradução nossa).

No centro do pensamento de Gramsci está a concepção dialética da história, na qual uma educação profissionalizante, segregadora e antidemocrática promovida e incentivada pela sociedade burguesa italiana tinha como fim atender demandas próprias da produção material de sua existência. Nesse contexto, a oferta da educação profissional é praticada na tentativa controlar ou absorver a antítese educacional revolucionária e com isso, controlar o próprio desenvolvimento histórico. Esse é o papel da ação propagandista que convence ideologicamente as classes subalternas dos benefícios econômicos da educação profissionalizante que passa a ser entendida como a solução, via inserção profissional dos subalternos, para os problemas próprios da organização do capital como a concentração da riqueza e o desemprego.

Gramsci, fundamentado em um historicismo absoluto, alertava que a antítese à organização educacional burguesa deveria se contrapor a produção e reprodução das condições materiais da existência humana próprias da sociedade burguês-capitalista. Por isso defendia, já em 1916, no texto Homens ou Máquinas?, que o proletariado precisava de uma escola desinteressada no trabalho industrial de natureza burguês-capitalista.

[...] Uma escola que não hipoteque o futuro da criança e não constrinja a sua vontade, sua inteligência, sua consciência em formação a mover-se por um caminho cuja meta seja prefixada. Uma escola de liberdade e de livre iniciativa, não uma escola de escravidão e de orientação mecânica. 
Também os filhos do proletariado devem ter diante de si todas as possibilidades, todos os terrenos livres para poder realizar sua própria individualidade do melhor modo possível e, por isso, do modo mais produtivo para eles mesmos e para a coletividade. (GRAMSCI, 2004, p. 75).

A antítese gramsciana é revolucionária e exprime a convecção de que a apropriação da cultura é o primeiro passo da passagem para o reino da liberdade. Ao propor a Escola Unitária, em contraposição a uma escola desagregadora da cultura e disseminadora da concepção de mundo burguesa, Gramsci, sobretudo, valorizava a formação cultural por meio de uma escola desinteressada na questão imediata da reprodução da vida material. A formação educativa pressuposta por ele tinha como fim preparar as crianças e os jovens para exercer seu papel social de cidadão, possibilitando que ao longo do processo educativo meninos e meninas se tornem "Homens", senhores da história, isto é, seres conscientes e capazes de operar a crítica sobre a sua própria concepção de mundo, de formular uma filosofia genuína a partir de suas necessidades individuais ou coletivas.

Pensando na realização plena do ser humano e, em uma clara contraposição ou antítese ao modelo educacional italiano de seu tempo, apresentou no Caderno 12 a concepção de Escola Unitária como um programa de organização da atividade educativa formal que, tendo como princípio educativo o trabalho em seu sentido ontológico, tinha o objetivo de superar a crise da tradição cultural e da concepção da vida e do homem, resultante da consolidação da sociedade burguês-capitalista.

A crise terá uma solução que, racionalmente, deveria seguir esta linha: escola única inicial de cultura geral, humanista, formativa, que equilibre equanimemente o desenvolvimento da capacidade de trabalhar manualmente (tecnicamente, industrialmente) e o desenvolvimento das capacidades de trabalho intelectual [...]. (GRAMSCI, 2007. p. 1531, tradução nossa).

Atenta à totalidade dos fenômenos que envolvem a educação escolar das classes subalternas, a concepção gramsciana de escola unitária se encontra fundamentada no desenvolvimento real da vida humana, produzida na relação intrínseca entre a sociedade civil e a sociedade política 9 .

Considerando o papel da Escola Unitária na formação das novas gerações, Gramsci ao pensar os objetivos da formação escolar de cunho unitário não deixou de considerar que a organização econômica do capitalismo industrial incide diretamente sobre as condições as quais as crianças e, sobretudo, os jovens chegam à escola. Primeiro a condição de reprodução material da vida na qual os filhos dos subalternos estavam submetidos e, em segundo, sobre o papel do Estado na oferta e garantia de uma educação voltada à formação cultural desinteressada das novas gerações.

A escola unitária ou de formação humanista (entendido este termo, 'humanismo', em sentido amplo e não apenas em sentido tradicional) ou de cultura geral deveria se propor a tarefa de inserir os jovens na atividade social, depois de tê-los levado a um certo grau de maturidade e capacidade, à criação intelectual e prática e a uma certa autonomia na orientação e na iniciativa. A fixação da idade escolar obrigatória depende das condições econômicas gerais, já que estas podem obrigar os jovens e as crianças a uma certa colaboração produtiva imediata. A escola unitária 
requer que o Estado possa assumir as despesas que hoje estão a cargo da família, no que toca à manutenção dos escolares [...]. (GRAMSCI, 2007. p 1534, tradução nossa).

Em função do aspecto dialético do pensamento de Gramsci e de sua habilidade para transitar entre o particular, a educação, e o geral, o contexto político, econômico e social no qual o sujeito está inserido, essa passagem do Caderno 12 pode gerar equívocos interpretativos por ocasião de uma leitura aligeirada. Um deles é decorrente da afirmação de Gramsci que destacou as condições da fixação da idade escolar obrigatória.

A afirmação de que: "A fixação da idade escolar obrigatória depende das condições econômicas gerais, já que estas podem obrigar os jovens e as crianças a uma certa colaboração produtiva imediata" (GRAMSCI, 2007. p 1534, tradução nossa), faz parte de uma constatação feita por Gramsci em relação a influência do contexto político e econômico de seu tempo sobre a organização escolar italiana. Portanto, não faz parte do programa da Escola Unitária e não é uma concessão de Gramsci diante das difíceis condições de produção da existência na Itália das primeiras décadas do século XX. Gramsci defendia que todas as crianças deveriam ter acesso à escolarização mas, para tanto, alertava para a necessidade de que, no que diz respeito a manutenção dos escolares, "[...] o Estado possa assumir as despesas que hoje estão a cargo da família [...]" (GRAMSCI, 2007. p. 1534, tradução nossa) ${ }^{10}$. Tal afirmação reforça o fato de que a Escola Unitária requer para se estabelecer como um programa de governo, nas condições econômicas características da sociedade capitalista, um aporte financeiro substancial por parte do Estado. Esse investimento deve se aplicado na estrutura escolar necessária para a permanência do estudante no ambiente escolar e em mecanismos de transferência de renda para as famílias em formas de bolsas de estudo.

Em outra passagem, mais adiante, quando Gramsci trata da organização práticapedagógica da Escola Unitária, afirma que esta deve se estender até os quinze ou dezesseis anos, dos quais os seis últimos, correspondentes a ao ensino médio devem ser os mais importantes na formação dos jovens dado que é nesse período que se consolida a apropriação da alta cultura. A apresentação da questão da idade da escolarização obrigatória é, portanto, uma evidência de uma contradição característica de uma sociedade. Deve-se retomar aqui a crítica empreendida por Gramsci no texto Homens ou Máquinas? no qual ele destacou que tanto a escola média de alta cultura quanto o ensino universitário, inacessível aos filhos dos grupos subalternos, eram custeadas, ao menos em parte, pelos impostos pagos pela classe trabalhadora.

Ao defender que o Estado deve assumir as despesas dessa educação, Gramsci se contrapõe a perspectiva de que a criança ou o jovem devam adiar os estudos em função das necessidades materiais. Perspectiva esta que, no entanto, não se consolida porque a lógica do capital fundada no acúmulo e na concentração de riqueza não prevê a socialização dos resultados da produção. Gramsci, portanto, não faz concessões diante da necessidade humana de produção material da existência. Para ele, estabelecer uma idade obrigatória para a entrada ou presença da criança ou do jovem na escola em função de sua inserção profissional era uma ação do governo fascista que, embora aparente ser uma ação democrática no campo da educação, acaba legitimando as diferenças sociais e a prática de expropriação do trabalho de jovens e crianças, agravados pela oferta de uma educação deficitária voltada a inserção dos subalternos no mercado de trabalho.

Gramsci defendeu uma educação igualitária para todos, independente de sua condição econômica ou classe social. É necessário estar atento para o fato de que ao 
descrever a Escola Unitária e apresentar o fim ao qual esta se destina, Gramsci usou a expressão "inserir o jovem na vida social", sem, no entanto, mencionar a questão da formação profissional ou a inserção do jovem no mercado de trabalho. Entretanto, deve-se ressaltar que a Escola Unitária é um programa de organização da educação em seus níveis elementar e intermediário, o que correspondente no atual sistema educacional brasileiro à educação básica e seus níveis de ensino, o fundamental e o médio. Para Gramsci, nessa fase da formação educacional das crianças e dos jovens, deve-se buscar na organização da Escola Unitária a apropriação das condições intelectuais necessárias ao domínio não só dos processos produtivos especializados, mas da organização dos meios de produção, tanto em sua face produtiva quanto do pondo de vista da organização política da sociedade.

Na proposição de um programa escolar como o da Escola Unitária, a síntese da dialética educacional desenvolvida a partir dela é incerta, mas deve ser estabelecida mediante a apresentação de uma antítese vigorosa que, contrapondo-se a concepção burguesa de organização escolar, expresse o máximo dos ideais almejados para a formação das novas gerações. Gramsci postulou que a Escola Unitária, ao se estender até o jovem completar quinze ou dezesseis anos, deve fornecer o aporte teórico-cultural necessário para que as novas gerações adquiram a autonomia e a disciplina. É por isso que os últimos anos da Escola Unitária são de grande importância porque ao promover o contato do jovem com a alta cultura, de cunho humanista e consolidar o domínio das habilidades físicas e intelectuais por meio da disciplina coroa todo o trajeto de formação iniciado na escola elementar antes de chegar aos estudos universitários.

[...] O estudo e o aprendizado dos métodos criativos na ciência e na vida deve começar nesta última fase da escola, e não deve ser mais um monopólio da universidade ou ser deixado ao acaso da vida prática: esta fase escolar já deve contribuir para desenvolver o elemento da responsabilidade autônoma nos indivíduos, deve ser uma escola criadora [...]. (GRAMSCI, 2007. p. 1537, tradução nossa).

Para Gramsci, “[...] na fase criadora, sobre a base já atingida de 'coletivização' do tipo social, tende-se a expandir a personalidade, tornada autônoma e responsável, mas com uma consciência moral e social sólida e homogênea [...]" (GRAMSCI, 2007. p. 1537, tradução nossa). A escola, portanto, deveria preparar a todos, independente de classe social ou situação econômica, para promover a reforma intelectual e moral, condição necessária a superação da concepção burguesa de mundo. A formação cultural dos subalternos se faz indispensável para a revolução e somente será alcançada quando a escola for organizada como fase decisiva da vida educativa e o humanismo for difundido a partir de seus valores essenciais, com ênfase na autodisciplina e na autonomia moral e intelectual, condições necessárias para um efetivo e posterior desenvolvimento da especialização profissional de caráter científico ou de caráter prático-produtivo.

A partir disso é possível afirmar que Gramsci era contra a formação profissional? Efetivamente que não. Gramsci defendeu a formação profissional como uma etapa posterior à formação de cultura geral. Na concepção educacional de Gramsci a formação profissional é complementar a formação escolar unitária. Por isso, Gramsci retira da escola elementar e média a tarefa de qualificação profissional, como afirmou que "[...] Deste tipo de escola única, através de repetidas experiências de orientação profissional, passar-se-á a uma das escolas especializadas ou ao trabalho produtivo [...]" (GRAMSCI, 2007. p. 1531, tradução nossa). Gramsci colocou o domínio da cultura como o centro da formação educacional ofertada nos níveis elementar e médio e enfatizou que o trabalho de formação 
cultural é imprescindível em qualquer programa educativo, principalmente se adotado pelo Estado.

No Caderno 4, nas notas $\S 51$ e $\S 72$ intituladas respectivamente de Braço e cérebro e $O$ novo intelectual, posteriormente retomadas e apresentadas ao final do Caderno 12 na nota $\S 3$, Gramsci abordou a questão dos intelectuais e a distinção entre trabalho intelectual e não intelectual. Nelas ele indicava a necessidade de formação de um novo tipo de intelectual, ligado ao mundo da produção e vinculado a ocupação prática do sujeito, afirmando que a formação cultural dos novos intelectuais deveria superar o espírito matemático e abstrato e se fundamentar em uma perspectiva científica e humanista da história, na qual o homem se tornava dirigente. Nesse sentido sentenciou que "[...] O modo de ser do novo intelectual não pode mais coexistir com a eloquência, motor exterior e momentâneo dos afetos e paixões, mas numa inserção ativa na vida prática, como construtor, organizador [...]" (GRAMSCI, 2007. p. 1551, tradução nossa).

O $\S 3$ do Caderno 12 é uma síntese de toda a reflexão de Gramsci sobre os intelectuais e ilustra a relação entre a formação cultural e a ação educativa da Escola Unitária. Ao afirmar que "[...] todo homem, fora de sua profissão, desenvolve uma atividade intelectual qualquer, ou seja, é um 'filósofo', um artista, um homem de gosto, participa de uma concepção de mundo [...]” (GRAMSCI, 2007. p. 1551, tradução nossa) Gramsci destacou o papel da formação cultural na constituição do próprio homem.

Cabe aqui retomar o $\S 44$ do Caderno 10. Nele o objetivo almejado pelo processo educativo apresentado por Gramsci no programa da Escola Unitária se desvela na medida em que a cultura que é o material de trabalho em busca da unitariedade se transforma e passa a ser o próprio produto de toda a relação educativa.

"[...] a relação pedagógica não pode ser limitada às relações especificamente 'escolares', através das quais as novas gerações entram em contato com as antigas e absorvem suas experiências e seus valores historicamente necessários, amadurecendo e desenvolvendo uma personalidade própria, histórica e culturalmente superior" (GRAMSCI, 2007. p. 1331, tradução nossa).

Se a questão da cultura serve de fundamento a sua crítica ao modelo educacional italiano, o debate sobre a formação cultural das novas gerações é resultado de suas reflexões sobre os intelectuais e sua inserção na sociedade. Esses intelectuais, de um tipo novo, portadores de uma cultura geral, capazes de produzir a crítica sua própria concepção de mundo, são os responsáveis por sintetizar teoricamente a produção resultante da ação contínua do homem de transformar a natureza e de produzir sua existência, de forma a torná-las um saber do qual as novas gerações possam se apropriar.

Esse processo de sistematização do real e sua efetivação enquanto saber científico, artístico e filosófico somente é possível de ser praticado quando os sujeitos envolvidos são detentores de habilidades intelectuais e práticas desenvolvidas ao longo de sua formação escolar. O trabalho educativo é a maior dádiva da formação escolar, pois ele permite que as novas gerações apreendam a se apropriar da produção cultural, artística, filosófica e científica, ao mesmo tempo em que desenvolvem a disciplina e autonomia necessárias à apropriação dos métodos de produção e sistematização da práxis em saber. 


\section{Conclusão}

As análises de Gramsci sobre a organização escolar italiana das primeiras décadas do século XX desvelam as contradições decorrentes do programa educacional do Estado italiano. Gramsci se contrapôs a essa organização escolar com um programa educacional vigoroso, a teoria da Escola Unitária.

A concepção de Escola Unitária, figura no pensamento de Gramsci como um programa educativo, estruturado a partir da compreensão das contradições imanentes à organização social, política e econômica da sociedade italiana das primeiras décadas do século XX.

Imbuído de uma práxis revolucionária, Gramsci enfatizou em seus escritos o papel da cultural geral na formação das novas gerações e inseriu na agenda educacional do século XX um programa educacional que, desinteressado na formação para o trabalho industrial, valorizava a escola como espaço de formação cultural, de promoção da autonomia e da consciência intelectual.

Ao propor a Escola Unitária como um programa educacional, Gramsci defendia uma escola, gratuita e de qualidade para todos, em que o trabalho educativo fosse desenvolvido com o objetivo de desenvolver as habilidades físicas e intelectuais de jovens e crianças difundindo a cultura geral entre as novas gerações.

\section{Referências}

ANGELI, José Mario. Gramsci, hegemonia e cultura: relações entre sociedade civil e política. Revista Espaço Acadêmico. Maringá. Ano IX, n. 122, p. 123-132, jul. 2011.

BARATTA, Giorgio. Cultura. In: LIGUORI, Guido; VOZA, Pasquale. (Org.).

Dizionario gramsciano 1926-1937. Roma: Carocci, 2009. p. 190-194.

CACCIATORE, Giuseppe. Storicismo. In: LIGUORI, Guido; VOZA, Pasquale. (Org.). Dizionario gramsciano 1926-1937. Roma: Carocci, 2009. p. 814-818.

CASTRO, Celso. Apresentação. In: (Org.). Evolucionismo cultural: textos selecionados de Morgan, Tylor e Frazer. Rio de Janeiro: Jorge Zahar, 2005. p. 7-40.

CUCHE, Denys. A noção de cultura nas ciências sociais. Bauru: Edusc, 1999.

DIAS, Edmundo Fernandes. Gramsci em Turim: a construção do conceito de hegemonia. São Paulo: Xamã, 2000.

FROSINI, Fabio. Da Gramsci a Marx: ideologia, verità e política. Roma: DeriveAprrodi, 2009.

GERRATANA, Valentino. Gramsci: problemi di metodo. Roma: Editori Riuniti, 1997.

GOMES, Jarbas Mauricio. Religião, educação e hegemonia nos Quaderni del Carcere de Antonio Gramsci. 2012. 216f. Dissertação (Mestrado em Educação) - Programa de PósGraduação em Educação. Universidade Estadual de Maringá, Maringá.

GRAMSCI, Antonio. Escritos Políticos, vol 1: 1910-1920. Organização e tradução de Carlos Nelson Coutinho. Rio de Janeiro: Civilização Brasileira, 2004.

GRAMSCI, Antonio. Quaderni del Carcere: Edizione crittica dell'Istituto Gramsci a cura di Valentino Gerratana. Torino: Einaudi, 2007. 4 vol.

LIGUORI, Guido. Roteiros para Gramsci. Rio de Janeiro: UFRJ, 2007. 
LOMBARDI, José Claudinei; MAGALHÃES, Lívia D. Rocha; SANTOS, Wilson da Silva. (Org.). Gramsci no limiar do século XXI. Campinas: Librorum Editora, 2013.

MAGRONE, Eduardo. Gramsci e a educação: a renovação de uma agenda esquecida. Cadernos Cedes. Campinas, vol. 26, n. 70, p.353-372, set/dez. 2006.

MANACORDA, Mario Alighiero. O princípio educativo em Gramsci: americanismo e conformismo. 2. ed. brasileira. Campinas: Alínea, 2008.

MARX, Karl.; ENGEL, Friedrich. Manifesto do Partido Comunista. São Paulo: Expressão Popular, 2008.

MARX, Karl. Prefácio. In: Contribuição à crítica da economia política. 2 ed. 2 reimp. São Paulo: Expressão popular, 2013. p. 45-50.

NOSELLA, Paolo. A escola de Gramsci. 3. ed. rev. e atual. São Paulo: Cortez, 2004.

NOSELLA, Paolo. Ensino Médio: em busca do princípio pedagógico. Educação e

Sociedade, Campinas. v. 32, n. 117, out/dez, 2011. p. 1051-1066.

NOSELA, Paolo; AZEVEDO, Mario Luiz Neves de. A educação em Gramsci. Revista Teoria e Prática da Educação. v. 15, n. 2, p. 25-33, mai/ago. 2012.

RIALL, Lucy. Il Risorgimento: storia e interpretazioni. Roma: Donzelli Editore, 1997.

SCHLESENER, Anita Helena. Revolução e cultura em Gramsci. Curitiba: UFPR, 2002.

TOGNON, Giuseppe. La riforma scolastica del ministro Gentile (1922-1924). In: SPADAFORA, Giuseppe (Org.). Giovanni Gentile: la pedagogia, la scuola. Roma: Armando Editore, 1997. p. 319-340.

TYLOR, Edward Burnett. A ciência da cultura. In: CASTRO, Celso (Org.).

Evolucionismo cultural: textos selecionados de Morgan, Tylor e Frazer. Rio de Janeiro: Jorge Zahar, 2005. p. 67-100.

Notas

\footnotetext{
${ }^{1}$ Mestre em Educação pela Universidade Estadual de Maringá (PPE-UEM), Maringá Paraná. Doutorando em Educação pela Universidade Federal de São Carlos (PPGE-UFSCar). Trabalho realizado com o apoio do Conselho Nacional de Desenvolvimento Científico e Tecnológico, CNPq.

Agradeço ao Prof. Paolo Nosella pela valiosa interlocução e pela generosidade de ler e contribuir para o amadurecimento das analises apresentadas. As citações cujo original remete ao texto em língua estrangeira são livres e do autor.

2 A edição descrita foi publicada entre 1999 e 2005. A primeira edição das Cartas e dos Cadernos do Cárcere foi publicada no Brasil entre 1966 e 1968. Hoje, para além destas edições é possível encontrar textos em diversas Antologias.

${ }^{3}$ A edição mais recomendada para o estudo dos Cadernos do Cárcere é a Edição Crítica, organizada por Valentino Gerratana e publicada em italiano em 1975, cuja edição mais recente é datada de 2007. Esta edição, que tem traduções para o Inglês e o Espanhol, é conhecida como Edizione Critica dell'istituto Gramsci a cura di Valentino Gerratana e publicou os 29 cadernos integralmente, mas não publicou os cadernos de tradução. Atualmente, o Instituto Gramsci tem incentivado a organização e publicação de uma nova edição dos Cadernos do Cárcere denominada de Nacional cujo projeto editorial objetiva a publicaçãodos 33 cadernos integralmente.

${ }^{4}$ Para uma visão geral da aproximação dos educadores brasileiros do pensamento de Gramsci recomenda-se a coletânea Gramsci no limiar do século XX organizada por José Claudinei Lombardi, Lívia D. rocha Magalhães e Wilson da Silva Santos, publicada em 2013.
} 
${ }^{5}$ O Risorgimento (Ressurgimento) foi o movimento político que se desenvolveu entre 1825 e 1879, a partir do qual se deu o processo de unificação da Itália. As análises de Gramsci sobre o Risorgimento permitem a compreensão dos problemas estruturais de ordem político-econômica decorrente das alianças desenvolvidas pela burguesia com as classes sociais envolvidas no processo de formação e desenvolvimento do Estado italiano (SCHLESENER, 2002).

${ }^{6}$ Edward Burnett Tylor (1832-1917) era natural da Inglaterra e mesmo pertencendo a uma próspera família de Londres não frequentou a Universidade. Em decorrência de suas viagens e em função de suas observações e dos livros que escreveu, é considerado por muito como o pai da antropologia cultural (CASTRO, 2009).

${ }^{7}$ Kultur é um termo alemão do século XVII que expressa uma visão da particularidade e serviam de fundamento para a crítica que os intelectuais das universidades faziam aos Príncipes dos diferentes Estados alemães. Kultur se opõe ao termo francês Civilization que expressa uma visão universalista de cultura produzida ao longo da consolidação do Estado. A crítica dos alemães era motivada pelo abandono da arte e da literatura pelos príncipes, que dedicavam seu tempo ao cerimonial da corte, preocupado em imitar as maneiras "civilizadas" da corte francesa (CUCHE, 1999).

${ }^{8}$ As Cartas do Cárcere escritas por Gramsci e destinadas aos seus filhos são um exemplo da defesa que Gramsci fez da formação intelectual dos jovens baseadas na apropriação da cultura geral. Sobretudo, da necessidade de desenvolver a disciplina de estudos adquirindo o domínio sobre a própria condição física e intelectual.

${ }^{9}$ A sociedade civil foi apresentada por Gramsci no Caderno $11, \S 65$ como o espaço natural das disputas hegemônicas de onde origina a ciência política (GRAMSCI, 2007. p. 1493, tradução nossa). No Caderno $6 \S$ 88, Gramsci postulou que o Estado é a síntese de duas sociedades distintas que coexistem, "[...] Estado = sociedade politica + sociedade civil, isto é, hegemonia couraçada de coerção" (GRAMSCI, 2007. p. 763-764, tradução nossa). A sociedade política é compreendida por Gramsci como a organização Estatal, que possui o poder político e a condição para o exercício da coerção por meio do direito legislativo; e a sociedade civil, que por sua vez, compreende os segmentos que não participam do governo do Estado, comporta a união dos cidadãos destituídos do poder governamental que adquire influência política a partir do consenso das massas reunidas em torno de instituições e organizações privadas como sindicatos e partidos políticos. Daí a importância atribuída por Gramsci à formação cultural dos membros das classes subalternas, dado que para ele esta é a real possibilidade de superação da hegemonia burguesa.

${ }^{10}$ Cabe lembrar aqui a passagem do Manifesto do Partido Comunista (MARX; ENGELS, 2008) onde ao discutirem as posições comunistas sobre a família burguesa, Marx e Engels expuseram o posicionamento dos comunistas em relação às crianças: "Vocês nos acusam de desejar abolir a exploração das crianças pelos pais? Nós confessamos esse crime" (p. 37) e ainda, "O palavrório burguês sobre família e educação, sobre a relação entre pais e filhos, torna-se mais repugnante quanto mais a grande indústria rompe os laços familiares dos proletários e as crianças são transformadas em simples artigos de comércio e instrumentos de trabalho" (p. 38).

Recebido em outubro-13

Aprovado em dezembro-13 